\title{
Necessidades formativas e condições de trabalho: desafios dos professores iniciantes em uma universidade pública
}

Nayana Cristina Teles nayanapsy@gmail.com http://orcid.org/0000-0002-5861-7674 Universidade Federal do Amazonas, Manaus, Amazonas, Brasil

\begin{abstract}
RESUMO
Este estudo se propõe a investigar as condições de trabalho e as necessidades formativas de professores dos cursos de licenciatura que estão iniciando sua trajetória docente no ensino superior. Foram entrevistados dois professores de uma universidade pública federal. Os principais resultados apontam que o processo de inserção profissional dos docentes não foi acompanhado de ação institucional; sua atuação está amparada nas representações sobre a docência construídas ao longo da trajetória acadêmica e reproduzidas de forma acrítica; e as necessidades formativas, quando percebidas, estão dissociadas do processo ensino-aprendizagem dos estudantes. Daí concluirmos a necessidade de programas de inserção à docência e de formação continuada institucionalizados e direcionados aos professores.
\end{abstract}

PALAVRAS-CHAVE: Professor Iniciante. Condições de Trabalho. Necessidades Formativas. 


\section{INTRODUÇÃO}

O presente estudo apresenta os resultados parciais de uma pesquisa desenvolvida no âmbito da disciplina Profissionalidade Docente de Professores Formadores dos Cursos de Licenciatura em Início de Carreira do Programa de Estudos Pós-Graduados em Psicologia da Educação, da Pontifícia Universidade Católica de São Paulo.

A pesquisa foi realizada em uma universidade pública, localizada na região norte, beneficiada, a partir de 2005, com os recursos do Programa de Apoio a Planos de Reestruturação e Expansão das Universidades Federais - REUNI, promovido pelo Governo Federal, que permitiu a criação de cinco novos campi, distribuídas ao longo do estado, identificados com a realidade regional de cada mesorregião em que foram implantados.

O campus no qual os dados foram coletados conta com dois cursos de licenciatura na área de ciências, um curso na área de saúde, dois cursos na área de informática e três cursos de engenharia. Por tratar-se de uma unidade localizada fora da capital do estado, e com todas as carências que os municípios no interior da região norte apresentam, tem enfrentado dificuldades na contratação de professores para algumas áreas do conhecimento, em contrapartida, tem atraído muitos profissionais recém saídos dos cursos de pós-graduação das diferentes regiões brasileiras, que veem nessa universidade a possibilidade de acesso à docência no ensino superior, por via de concurso público, com menor concorrência do que aquela enfrentada em suas cidades/estados de origem.

Assim, a universidade na qual foram entrevistados os dois professores que compõem a amostra desse estudo tem recebido, nos seus oito anos de funcionamento, muitos professores iniciantes na docência do ensino superior, que assumiram a responsabilidade de implementar o campus, construir o projeto pedagógico curricular dos cursos de graduação, respondendo por atividades administrativas, pedagógicas, de ensino, extensão e pesquisa, características das universidades públicas.

Diante deste quadro, a pesquisa na qual se integra este estudo se propõe a investigar os processos de constituição da profissionalidade docente de professores dos cursos de licenciatura que estão iniciando sua trajetória docente no ensino superior. A investigação está centrada na perspectiva de que a presença de um corpo docente renovado vem atuando nos cursos de formação de professores, cujas condições de trabalho, de socialização e desenvolvimento profissional merecem ser investigadas e analisadas em conjunto com as políticas de formação docente e seus impactos na efetivação dos cursos de licenciatura.

Neste trabalho o foco da análise centrou-se nas seguintes questões: quais as condições de trabalho e as necessidades formativas dos professores formadores das licenciaturas em seu processo de inserção profissional?; como percebem a sua atuação nos cursos de licenciatura?

Para a construção do referencial teórico e posterior leitura e análise dos dados nos amparamos nos estudos de Vaillant e Garcia (2012), Garcia (2006), Cunha (2005, 2009, 2010), Lima (2013) e Tancredi (2009), dentre outros.

O texto se inicia tecendo considerações acerca do contexto de expansão e interiorização do ensino superior no Brasil, situando o lócus do estudo nessa 
política pública com seus limites, dificuldades e possibilidades. Em seguida pontua os achados da literatura sobre o professor iniciante, condições de trabalho e necessidades formativas que auxiliaram na leitura e análise dos dados. Após a caracterização dos sujeitos são apresentados e discutidos os dados que possibilitaram problematizar as questões propostas, para em seguida concluir com as considerações acerca dos principais achados.

\section{EXPANSÃO E INTERIORIZAÇÃO DO ENSINO SUPERIOR: DESAFIOS DA UNIVERSIDADE DIANTE DAS NOVAS REALIDADES}

A partir de 2003, com a posse do então presidente Luís Inácio Lula da Silva, a política pública direcionada a expansão do ensino superior sofreu algumas mudanças e redirecionamentos. Até então, o absoluto do sistema educacional de nível superior concentrava-se no segmento particular, e, parte da proposta do novo governo implicava redirecionar recursos e aumentar o número de matrículas no segmento federal, sucateado e estagnado em decorrência da política adotada pelo governo anterior.

No ano de 2005 foi inaugurado o programa Universidade Aberta do Brasil (UAB), cujos principais objetivos são ampliar e interiorizar a oferta de cursos e programas de educação superior, por meio da educação à distância, e reduzir as desigualdades na oferta de ensino superior, desenvolvendo um amplo sistema nacional de educação superior à distância (BRASIL, 2016).

Ainda como parte da política de expansão da oferta de vagas, o governo federal lançou o Programa de Apoio a Planos de Reestruturação e Expansão das Universidades Federais (Reuni) para o período de 2008 a 2012, que tem por objetivo

\footnotetext{
Criar condições para a ampliação do acesso e permanência na educação superior, no nível de graduação, para o aumento da qualidade dos cursos e pelo melhor aproveitamento da estrutura física e de recursos humanos existentes nas universidades federais, respeitadas as características particulares de cada instituição e estimulada a diversidade do sistema de ensino superior (BRASIL, 2007, p. 10).
}

Segundo Carvalho (2014, p. 222) "a política de expansão extensiva e intensiva do segmento federal no governo Lula tinha por objetivo reduzir as distâncias geográficas e as desigualdades da educação superior em termos regionais [...]". Tal intuito concretizou-se na abertura de novos campi das universidades federais, principalmente no interior dos estados, bem como pela criação de novas universidades federais, localizadas em cidades interioranas. Ainda conforme Carvalho (2014), a redução das desigualdades regionais ficou a cargo do segmento federal, já que a iniciativa privada não apresenta, necessariamente, preocupações de ordem social ou de redistribuição espacial.

Aderindo ao Reuni, a universidade na qual foi realizada esta pesquisa inaugurou, nos anos de 2007 e 2008, cinco campi, localizados em cidades interioranas, algumas acessíveis apenas por avião ou barco, com a abertura de 30 novos cursos distribuídos nestes campi. As características típicas das cidades do interior da região norte que não contam com adequada infraestrutura de saúde, lazer e serviços, dificulta a adaptação na cidade, principalmente dos professores 
oriundos de outras regiões do país, que compõe parcela significativa dos 130 docentes dessa instituição.

A cidade onde está localizada essa universidade, contava, até 2007 , com cursos oferecidos pela $U A B$ nas áreas de licenciatura, além iniciativas fragmentadas de cursos superiores ofertados por universidades públicas em parceria com a prefeitura, resultando na demanda por grande contingente de jovens e adultos de formação em nível universitário.

Uma das metas do Reuni é a ampliação da oferta aliada a diminuição do número de vagas ociosas, entretanto, no campus em questão, o número de vagas ociosas, somadas a alta taxa de evasão e retenção impõem-se como desafios a atuação dos professores.

Conforme relata Carvalho (2014, p. 235), a política pública direcionada ao ensino superior já prévia que:

[...] a melhoria no acesso à educação superior está diretamente atrelada ao financiamento da demanda, mas isso não é suficiente. Torna-se necessário dar condições de permanência à população estudantil, sobretudo, aquela proveniente das camadas sociais mais pobres [...].

Percebemos nesta universidade que as políticas de assistência estudantil se constituem em mecanismos fundamentais para a permanência dos alunos, pois, representativa parcela destes estudantes vem das camadas populares. Além disso, faz-se necessário um grande esforço e investimento para a superação das desigualdades escolares que impedem muitos destes jovens de progredirem nos cursos.

Assim, é preciso considerar, no contexto da consolidação destes campi, que as desigualdades sociais e regionais se constituem como aspectos importantes a serem ponderados pela política de acesso ao ensino superior como obstáculos a serem superados.

\section{PROFESSORES INICIANTES NO ENSINO SUPERIOR: INSERÇÃO PROFISSIONAL, NECESSIDADES FORMATIVAS E CONDIÇÕES DE TRABALHO}

Uma das premissas da presente pesquisa é a existência de um corpo docente renovado atuando nos cursos de formação de professores. Nessa perspectiva, nos indagamos sobre como vem ocorrendo a inserção destes profissionais na docência, quais suas condições de trabalho e que necessidades formativas possuem, ou não, para atuarem como formadores de professores.

No ensino universitário, professor principiante é aquele com menos de três a cinco anos de experiência docente em uma instituição universitária (BOZU, 2010). Este período de iniciação ao ensino representa o ritual de passagem de aluno a professor, no qual a integração da cultura docente a personalidade do professor, bem como sua adaptação ao entorno social se constituem em processos da socialização profissional com peso decisivo na vivência dessa fase como uma experiência satisfatória.

Este período de iniciação profissional deve ser compreendido como parte de "[...] um contínuo processo de desenvolvimento profissional dos docentes" (VAILLANT; MARCELO, 2012, p. 125), que merece atenção especial por marcar, de 
forma significativa, a atuação docente, constituindo "[...] as primeiras experiências de trabalho como fundantes dos saberes que constroem" (CUNHA, 2005, p. 89).

No período de iniciação profissional os contextos de trabalho têm grande importância, pois, como aponta Cunha (2009, p. 17) são em geral muito "[...] desiguais, complexos e instáveis [...]", exigindo dos professores que os conheçam, interpretem e sobre eles atuem de acordo com suas particularidades. Na pesquisa aqui apresentada o contexto de atuação dos docentes se reveste de particular importância, já que estes professores são oriundos de grandes capitais brasileiras e tiveram sua formação em universidades públicas que atendem a alunos com características diversas daqueles que encontraram em sua prática como docentes. Nesse sentido, cabe a colocação de Garcia (2006) para quem a adaptação ao entorno sociocultural pode ser mais fácil se este coincide com características familiares ao professor principiante.

Nos alerta Tancredi (2009) que embora a docência seja uma profissão desvalorizada, torna-se cada dia mais complexa, exigindo profissionais capacitados e dispostos a aprender ao longo da vida. Os sujeitos desta pesquisa são dois professores das áreas de física e química, recém-saídos de cursos de pósgraduação, em sua primeira atuação como docentes. A formação recebida por estes professores em seus cursos de graduação e pós-graduação corresponde a concepção epistemológica dominante, especialmente nas ciências exatas e da natureza, na qual o conhecimento do conteúdo específico, e nessa linha, o privilégio da pesquisa do tipo aplicada, adquirem maior relevância em detrimento aos saberes pedagógicos. Diante dessa realidade cabe indagar se a atuação concreta em sala de aula despertou esses docentes para as suas necessidades formativas, posto que, no contexto da própria universidade, o que se estabelece é a ênfase na dimensão científica do docente, através da pós-graduação.

Para pensar as necessidades formativas dos docentes, caminharemos na direção proposta por Benedito, Imbernón e Félez (2001) para quem as necessidades formativas adquirem um caráter polissêmico, cujo dilema pode ser resolvido pela adoção de perspectiva dual e dialética, na qual

Necessidade é tanto o conjunto de aspectos considerados inerentes ao desenvolvimento dos professores novos sem o qual se pode afirmar que possuem uma carência formativa, como o que o professorado manifesta como necessário e do qual deseja obter uma capacitação para poder realizálo (BENEDITO; IMBERNÓN; FÉLEZ, 2001, p. 3).

De posse dos conceitos acima discutidos e de outros que nos serviram como referência ao presente estudo, traremos a seguir os principais achados da pesquisa, coletados a partir da fala dos docentes entrevistados.

\section{QUEM SÃO OS PROFESSORES INICIANTES E O QUE OS LEVA A OPTAR PELA DOCÊNCIA?}

Para a coleta de dados utilizamos uma entrevista semiestruturada aplicada na própria universidade, com o consentimento livre e esclarecido dos participantes.

Os docentes foram escolhidos por atenderem aos seguintes critérios: serem professores formadores dos cursos de licenciatura, estarem a menos de três anos 
no exercício do magistério no ensino superior, e pela facilidade de acesso a esse campus.

O professor de física tem 30 anos e está há dois anos nessa instituição, é formado em licenciatura em física, com doutorado também nessa área, já o professor de química tem 30 anos e está há menos de um ano nessa instituição, sua graduação foi bacharelado em química com doutorado na área.

O caminho traçado por estes sujeitos no ensino superior é bem semelhante, ambos concluíram a graduação e em seguida adentraram a pós-graduação, cursando mestrado e doutorado ininterruptamente. Igualmente dedicaram-se a pesquisa aplicada em suas dissertações e teses. Relataram não ter tido, nos cursos de pós-graduação, disciplinas pedagógicas, embora percebam de forma diferente essa ausência, desnecessária para o Prof. de Física e necessária para o professor de química, que relata sentir-se despreparado para a docência: "o pessoal saí de lá [curso de pós-graduação] muito despreparado, sem nenhuma formação orientada para ser professor, nossa educação é para ser pesquisador".

A opção pela docência no ensino superior apresenta-se de forma diversa a esses dois docentes, o professor de física opta pela carreira docente por desejar trabalhar com pesquisa e por gostar de estudar, atividades valorizadas nesta carreira e que para ele representam "qualidade de vida". Já o Prof. de Química faz essa opção por vê-la como melhor caminho diante do título que possui

\footnotetext{
Porque depois eu comecei a imaginar o que eu iria conseguir fazer com esse título de doutor no meu currículo, e você sabe que são raras as empresas que realmente tenham comprometimento ou interesse com alguém com uma qualificação acima da graduação trabalhando na indústria. Normalmente esses trabalhadores vão para a área de pesquisa, que é realmente bastante seleto, bastante difícil de você conseguir entrar (PROF. DE QUÍMICA).
}

Diante da concorrência presente nos concursos públicos para a docência universitária, principalmente nas regiões sul e sudeste, da qual são oriundos estes sujeitos, a universidade na qual atuam se constituiu em uma boa opção para a inserção na carreira.

\section{CONDIÇÕES DE TRABALHO E NECESSIDADES FORMATIVAS: DESAFIOS DO PROFESSOR INICIANTE}

É no contexto de trabalho no qual atuam que os docentes terão de construir a sua profissionalidade, tendo de cumprir duas tarefas essenciais: ensinar e aprender a ensinar (MARCELO, 2006), definindo estilos de docência e construindo conhecimentos que servirão de base a sua atuação profissional. Assim, buscamos no diálogo com os professores entrevistados, conhecer como se deu o início de sua atuação como docentes, quais os desafios enfrentados e quais necessidades formativas possuem, ou não.

Com o intuito de identificar as condições de trabalho e seu impacto na atuação dos docentes formadores dos cursos de licenciatura, questionamos os sujeitos sobre a estrutura física e os recursos didáticos de que dispõe nesse campus, a forma como foram recebidos nesta instituição, se contam, ou não, com momentos de trabalho coletivo ou reuniões pedagógicas, além da existência (e se percebem como necessária) de formação continuada. 
Sobre a estrutura física o Prof. de Física relata:

É ruim, é ruim. Até pela estrutura do Instituto, não tem laboratório, eles [os alunos] não têm aula nenhuma de laboratório [...] o legal é uma ciência experimental, você tem que ver a experiência, para depois matematizar o problema, nas universidades lá fora é isso que acontece.

A ausência de uma estrutura física adequada, segundo este professor, impacta na aprendizagem dos alunos e o leva a comprar materiais com recursos próprios, no intuito de proporcionar melhor compreensão dos alunos sobre a matéria.

O Prof. de Química destaca que é necessária uma melhor estrutura de laboratórios na universidade, porém, credita ao pouco tempo de existência da mesma estas carências, que não impactam ainda tão fortemente em sua atuação como docente por trabalhar com disciplinas teóricas, que não requerem tal recurso.

Porém, os dois professores alegam que a infraestrutura deficitária, principalmente de laboratórios e internet, prejudica o desenvolvimento da pesquisa dentro de seu campo de atuação.

Ainda se tratando das condições de trabalho, no que se refere ao acolhimento recebido no seu ingresso na instituição e ao apoio didático, ambos relatam ter recebido uma acolhida "burocrática", na qual foram apresentados ao local e as suas normas gerais de funcionamento.

O apoio didático é buscado nas conversas informais com os colegas ou com outros sujeitos externos a esse ambiente, como é o caso do Prof. de Física que busca auxílio junto ao seu orientador de doutorado. Como é comum há muitas universidades brasileiras, esta instituição não possui um programa de iniciação à docência ou de formação continuada.

Perguntados sobre a existência de reuniões pedagógicas ou de trabalho coletivo, os dois professores respondem que não há momentos específicos e institucionalmente definidos para tal, mas que os docentes costumam compartilhar suas experiências, trocar informações e discutir assuntos pedagógicos em encontros informais.

O momento institucionalizado para a discussão das decisões a serem tomadas nos cursos, dos problemas enfrentados e o processo de reestruturação dos projetos pedagógicos acontece nas reuniões de colegiado e dos Núcleos Docentes Estruturantes, porém, nessas reuniões não são discutidas questões didáticopedagógicas ou relacionadas à atuação dos professores.

Diante da ausência de atenção por parte da universidade aos professores principiantes em seu processo de inserção profissional, dois desafios que se colocam a atuação docente sobressaem na fala dos entrevistados: a ausência de uma preparação específica para a docência e o perfil dos alunos.

O Prof. de Química faz um significativo relato do início de sua atuação como docente nesta universidade:

Foi horrível! Foi realmente difícil [...] eu acho que acabei ficando muito nervoso, muito nervoso mesmo, senti minha voz trêmula, tinha que segurar minha mão senão ela acabava tremendo, visivelmente nervoso [...] e logo que eu saí da sala de aula achei que eu tinha mergulhado em uma piscina de 
roupa, de tão suado, transpirando demais, e não foi só na primeira aula não levou uns belos dois meses e meio para parar com essa situação [...].

Este professor precisou superar sozinho os desafios do processo de inserção profissional, aprendendo, em suas palavras "na marra" e por "ensaio e erro" a atuar como docente, tendo como referência a imitação dos professores que marcaram positivamente a sua trajetória acadêmica.

Quando questionado sobre a necessidade de um programa de formação continuada para os professores formadores dos cursos de licenciatura, o Prof. de Química afirma que seria de grande importância:

[...] principalmente para os professores iniciantes que não possuem nenhuma base pedagógica, nós sabemos que não é pré-requisito que o professor tenha alguma atividade pedagógica, ou cursado alguma atividade pedagógica para ser professor de uma instituição de nível superior, então eu acho que isso é uma falha, uma falha bem grande porque os professores chegam muito despreparados. Eu falo por mim mesmo pelo que aconteceu, eu cheguei completamente despreparado.

Contrapondo-se a essa percepção, o Prof. de Física vê como desnecessária qualquer atividade voltada a formação pedagógica, pois cabe aos professores buscarem o conhecimento necessário à sua prática.

Percebemos nessas falas o que descreve Cortesão (apud CUNHA, 2005): os professores universitários ensinam da forma como foram ensinados, reproduzindo e perpetuando práticas de ensino mais ou menos eficientes, em uma transmissão mais ou menos eficaz de saberes

É interessante notar que embora o professor de química perceba o seu despreparo diante da docência, não o relaciona as dificuldades enfrentadas pelos alunos e assim como o professor de física, foca no perfil dos estudantes os principais entraves a consecução da aprendizagem e desafio a sua atuação como professor.

Na fala destes dois sujeitos os alunos não tem pré-requisitos para o ingresso no ensino superior, falta-lhes a formação de base:

[...] agora ele entrou aqui e não sabe somar fração [...] os nossos alunos são analfabetos em Matemática, e aí tem que ensinar Cálculo I pra ele em 4 meses, sendo que ele não sabe somar fração, eles entendem o processo, eles conseguem integrar, conseguem fazer a derivada, isso eles entendem, o que eles não entendem é o meio do caminho, eles erram nas contas, eles não sabem, como eles nunca aprenderam a somar fração, eles não sabem somar $1 / x+1 / y$, parte para essa parte abstrata e acabou o aluno, se ele tivesse aprendido a somar fração, o processo de somar fração, ele saberia somar letras, somar as variáveis, mas ele não aprendeu, então é difícil demais para eles isso, é uma barreira, o cara tem que se dedicar demais, isso seria básico pro curso [...] (PROF. DE FÍSICA).

[...] eles chegam num nível que, eu não sei, me causa muita tristeza, saber que alunos de 16, 17 e 18 anos que entram aqui na universidade, são praticamente analfabetos funcionais, eles sabem escrever o nome [...] nas provas eu sempre as faço dissertativas, então eu perguntava e pedia para eles justificarem a resposta (pausa) era triste, era triste, era cômico ler as respostas, mas era triste ler isso vindo de um aluno que está em uma instituição federal [...] o que acaba sendo um problema muito sério para cá, como a gente tem uma demanda, uma oferta muito grande de posições na 
sala de aula, mas tem uma procura muito baixa, a gente acaba recebendo alunos que não são adequados para ter essa posição [...] (PROF. DE QUÍMICA).

Embora a descrição das dificuldades dos alunos desta universidade pelos professores entrevistados não seja falsa ou exagerada, e de certo tais características dificultam a construção dos saberes necessários à sua formação profissional, cabe questionar o papel dos professores no enfrentamento destas dificuldades, posto que, faz-se necessário que os docentes questionem as suas práticas e reflitam sobre a sua adequação ao aluno concreto que recebem em suas salas de aula. Há uma ênfase maior nas dificuldades percebidas nos alunos do que nas suas próprias dificuldades didático-pedagógicas.

Cabe pontuar que o processo de interiorização e massificação do ensino superior permitiram o acesso de um contingente de alunos que até então era excluído já no processo seletivo. Hoje esses alunos adentram a universidade e sofrem um outro processo de exclusão, por não possuírem a preparação científica desejada, não conseguindo progredir e concluir a graduação.

Quando se trata das próprias necessidades formativas, o Prof. de Física parece possuir uma percepção bastante limitada dos saberes necessários a atuação docente, centrada no saber do conteúdo, já o Prof. de Química, embora reconheça a necessidade de uma formação pedagógica que o auxilie na interação com os alunos e na transmissão do conteúdo, não tem clareza da forma como a mesma pode ser trabalhada em um processo de formação voltada aos docentes.

Trazemos a contribuição de Lima (2013, p. 16) que alerta: “[...] Há que se problematizar a diferença entre a percepção (subjetiva, portanto) das necessidades de formação por parte dos docentes, cotejando-as com as necessidades postas pela universidade e pelo mundo atual e futuro [...]". Esta ideia coaduna com a de Benedito, Imbernón e Félez (2001) para quem as necessidades expressas e sentidas não devem ser a única fonte para a detecção das necessidades formativas, pois as mesmas limitam-se aos aspectos do ensino que os docentes conhecem.

Dessa forma a construção de propostas de inserção profissional e de formação continuada precisam ir além das necessidades levantadas pelos docentes, considerando as demandas da universidade e dos novos alunos que a frequentam.

\section{A ATUAÇÃO DO PROFESSOR INICIANTE NOS CURSOS DE LICENCIATURA: OLHAR NEGATIVO SOBRE A PROFISSÃO DE PROFESSOR}

A escolha pela docência no ensino superior para estes dois docentes, embora com motivações diversas, trazem em comum o desejo de continuar a carreira de pesquisadores.

O Prof. de Física ao ser questionado porque escolheu a docência responde: "Pela pesquisa. Eu gosto de estudar, eu acho bacana isso de estudar [...]". A escolha dessa universidade levou em consideração a possibilidade de continuar a pesquisar "[...] Aí eu vi que tinha física, matemática, eu vi que tinha um grupo de pesquisa [...] aí eu falei 'vai dar para eu continuar a minha pesquisa', o que é legal, academicamente eu não ia estar morto". 
O peso da pesquisa também surge na fala do Prof. de Química como determinante de sua opção pela docência e pela universidade em questão "[...] eu sempre tive muita vontade de ir para a área de pesquisa, saber que aqui havia o curso de química, no qual pudesse ter um mestrado também, onde a gente pudesse ter alunos de química participando [...]".

Quando perguntamos o porquê da escolha de trabalhar em um curso de licenciatura, ambos responderam que não se tratou de uma escolha e sim de se adequar aos cursos existentes nesta universidade, conforme destaca o Prof. de Física: "Eu não escolhi. É o que tem, é o que tem aqui, o curso de licenciatura, acho importante também, o curso de licenciatura, aqui precisa de professor, o estado, como política pública eu entendo que é necessário [...]".

Porém, percebemos fortemente na fala desses sujeitos uma percepção bastante negativa da docência na educação básica, apesar de compreenderem a necessidade de formar professores, inclusive para melhorar a qualidade dos alunos que chegam à graduação.

[...] mas pro indivíduo eu me sinto mal, você olhar pro aluno e falar "eu vou tornar você um professor", eu me sinto mal com isso, porque eu não quero pra mim, e o que eu não quero pra mim não quero fazer para os outros. Então se o cara falar para mim, olha professor eu adoro isso, eu quero ser professor do estado, trabalhar muito e ganhar pouco, eu gosto disso, então vai em frente, né, eu vou te apoiar. Agora se falar, assim como os alunos vem e falam comigo "professor, eu dou aula para o estado e não aguento mais, me tira disso, eu quero fazer pesquisa, eu quero mudar, me preparar para um mestrado", vamos embora, eu vou te ajudar, e é sempre isso que acontece [...] (PROF. DE FÍSICA).

Eu não conseguiria recomendar ao aluno em sã consciência, eu sei que é triste falar isso, mas eu não conseguiria recomendar ele a fazer um curso como esse pelo que ele vai enfrentar no futuro (PROF. DE QUÍMICA).

As razões alegadas pelos professores para essa percepção negativa da docência são a desvalorização social da carreira, os baixos salários, o excesso de trabalho e as condições desfavoráveis encontradas nas escolas.

Para esses docentes, o aluno da licenciatura não tem clareza de sua opção profissional ou vocação para a carreira, tampouco habilidade para as áreas específicas (matemática, física, química), estão no curso pela baixa procura em relação a oferta de vagas, o que facilita o acesso.

Cabe refletir o quanto a desvalorização da licenciatura dentro da universidade influi na percepção que os alunos têm da carreira, e embora reproduza a visão da sociedade sobre a profissão, perpetua esta desvalorização.

Também é importante considerar a forma como os professores formadores das licenciaturas têm sido escolhidos para atuar nesses cursos, pois não se identificam com os mesmos, além de não possuírem formação específica para neles atuar, tendo trilhado em seu processo de formação o caminho da pesquisa aplicada, sem experiências formativas na educação básica. Talvez a ausência desses pré-requisitos na seleção destes docentes se deva a visão ainda presente nas universidades na qual para ser professor o essencial é o domínio do conteúdo, ancorado no pressuposto de que a pesquisa qualifica o ensino (CUNHA; ZANCHET, 2010). 


\section{CONSIDERAÇÕES FINAIS}

O processo de inserção profissional do professor do ensino superior embora venha recebendo atenção pelos pesquisadores do campo de formação docente, permanece um assunto silenciado no cotidiano de significativa parcela das universidades brasileiras.

Os desafios enfrentados por esses docentes têm sido resolvidos pelo empenho individual destes profissionais, que sem amparo institucional, contam com a colegialidade dos colegas e acabam adentrando ao processo de socialização da profissão pela reprodução de práticas institucionalizadas que não são questionadas.

Cabe ressaltar que um professor só pode chegar a ser especialista pela reflexão sobre a sua conduta, se não reflete sobre a sua prática, não chegará a um pensamento e conduta especializados (VAILLANT e MARCELO, 2012).

Daí concluímos que uma formação inicial pedagógica como parte dos programas de pós-graduação strictu sensu pode ser uma opção válida como processo de formação inicial para a docência no ensino superior, pois é o trabalho na universidade que absorve significativa parcela destes profissionais.

Esta formação pedagógica inicial não descarta a necessidade de programas de inserção docente nas instituições e de sua continuidade em programas de formação continuada, coerente com a compreensão de que o desenvolvimento profissional do professor é um processo contínuo e exigente que se dá ao longo da vida.

O perfil dos docentes que atuam nos cursos de licenciatura também merece atenção, pois na universidade investigada, não parece existir consonância entre a trajetória acadêmica e profissional dos professores do curso e as necessidades específicas de uma licenciatura. Diante desse quadro é de se esperar a existência de necessidade formativas específicas que influem na atuação destes professores nas licenciaturas e que são merecedoras de atenção.

O discurso dos professores investigados sobre o curso de licenciatura e a docência na educação básica condiz com o que já alertava Gatti e Nunes (2009) sobre o lugar secundário ocupado pela formação de professores na universidade brasileira

Dentro desse quadro, a formação de professores é considerada atividade de menor categoria e quem a ela se dedica é pouco valorizado. Decorre daí uma ordem hierárquica na academia universitária, as atividades de pesquisa e de pós-graduação possuem reconhecimento e ênfase, a dedicação ao ensino e à formação de professores supõe perda de prestígio acadêmico (GATTI; NUNES, 2009, p. 152).

Os docentes entrevistados vivenciaram em suas formações a realidade acima descrita, adotando essas representações na sua atuação como professores do ensino superior, por esse motivo, embora o campus no qual se realizou este estudo tenha apenas oito anos de funcionamento, é uma universidade nova com velhas práticas, pois na ausência de momentos de 
discussão institucionalizados e de reflexões coletivas teoricamente fundamentadas sobre concepções de docência, papel da universidade e dos cursos de graduação, permanece a reprodução acrítica de representações e práticas já institucionalizados.

Há que se valorizar, entretanto, o esforço empreendido por estes docentes, que mesmo diante dos desafios enfrentados no processo de inserção profissional buscam proporcionar aos alunos a aquisição dos conhecimentos por eles julgados necessários à sua formação profissional, demonstrando preocupação com a formação dos estudantes e sua inserção no mercado de trabalho. 


\title{
Formation requirements and working conditions: challenges of teachers beginners in a public university
}

\begin{abstract}
This study aims to investigate the working conditions and the training needs of teachers of degree courses who are starting their teaching career in higher education. Interviews were conducted with two professors from a public university. The main results show that the professional insertion process of teachers has not been accompanied by institutional action; his performance is supported in the representations of teaching built along the academic path and reproduced uncritically; and training needs, when realized, are separated from the teaching-learning process of students. It is concluded that it is necessary to invest in institutionalized integration programs to teaching and continuing education and targeted to teachers.
\end{abstract}

KEYWORDS: Inexperienced Teachers. Work Conditions. Training Needs. 


\title{
Requisitos de formación y condiciones de trabajo de los profesores: retos de profesores principiantes en una universidad pública
}

\author{
RESUMEN
}

Este estudio tiene como objetivo investigar las condiciones de trabajo y las necesidades de formación de los profesores de los cursos de grado que están iniciando su carrera de enseñanza en la educación superior. Entrevistamos a dos profesores de una universidad pública. Los principales resultados muestran que el proceso de inserción profesional de los docentes no ha sido acompañado por la acción institucional; su actuación se apoya en las representaciones de la enseñanza construida a lo largo de la trayectoria académica y reproducido sin crítica; y las necesidades de formación, cuando se dio cuenta, se separan del proceso de enseñanza-aprendizaje de los estudiantes. Por lo tanto nos encontramos con la necesidad de insertar los programas de enseñanza y institucionalizada y dirigida a los profesores de educación continua.

PALABRAS-CLAVE: Profesor Principiante. Condiciones de Trabajo. Necesidades de Formación. 


\section{REFERÊNCIAS}

BRASIL. Ministério da Educação. REUNI: Reestruturação e expansão das universidades federais: diretrizes gerais. 2007. Disponível em:

<http://portal.mec.gov.br/sesu/arquivos/pdf/diretrizesreuni.pdf $>$. Acesso em: 21 maio 2016.

BRASIL. Ministério da Educação. Universidade Aberta do Brasil. Histórico. 2016. Disponível em: <http://www.capes.gov.br/component/content/article?id=7838>. Acesso em: 27 jun. 2016.

BENEDITO, V., IMBERNÓN, F., FÉLEZ, B. Necesidades y propuestas de formación del profesorado novel de la Universidad de Barcelona. Profesorado. Revista de Currículum y Formación del Profesorado, Granada/Espanha, 2001, vol. 5, n. 2. Disponível em: $\leq$ http://www.ugr.es/ recfpro/rev52ART4.pdf $>$. Acesso em: 13 jul. 2015.

BOZU, Z. El profesorado universitario novel: estudio teórico de su proceso de inducción o socialización profesional. Revista Electrónica de Investigación y Docencia (REID), Espanha, 2010, n.4, p.55-72. Disponível em:

<http://www.ujaen.es/revista/reid/revista/n3/REID3art3.pdf>. Acesso em: 12 jul. 2015.

CARVALHO, C. H. A. Política para a educação superior no governo Lula: expansão e financiamento. Revista do Instituto de Estudos Brasileiros, São Paulo, 2014, n. 58, p. 209-244. Disponível em:

<http://www.revistas.usp.br/rieb/article/view/82397>. Acesso em: 21 maio 2016.

CUNHA, M. I. (Org.). Formatos avaliativos e concepção de docência. Campinas: Autores Associados, 2005.

CUNHA, M I. O lugar da formação do professor universitário: o espaço da pósgraduação em educação em questão. Revista Diálogo Educacional, Paraná, 2009, v.9, n. 26, p. 81-90. Disponível em: <http://www2.pucpr.br/reol/index.php/ dialogo?dd99=pdf\&dd1=2585>. Acesso em: 13 jul. 2015.

CUNHA, M. I.; ZANCHET, B. M. B. A. A problemática dos professores iniciantes: tendência e prática investigativa no espaço universitário. Educação, São Paulo, 2010, v. 33, n.3, p. 189-197. Disponível em:

<http://revistaseletronicas.pucrs.br/ojs/index .php/faced/article/ viewFile/6999/5717>. Acesso em: 13 jul. 2015. 
GATTI, B. A., NUNES M. M. R. (Orgs). Formação de professores para o ensino fundamental: estudo de currículos das licenciaturas em pedagogia, língua portuguesa, matemática e ciências biológicas. São Paulo: FCC/DPE, 2009.

LIMA, E. F. Análise de necessidades formativas de docentes ingressantes numa universidade pública. 36a Reunião Nacional da ANPEd, Anais...Goiânia, 2013. Disponível em:

<http://36reuniao.anped.org.br/pdfs trabalhos aprovados/gt08 trabalhos pdfs /gt08 2779 texto.pdf>. Acesso em: 13 jul. 2015.

MARCELO, C. G. Políticas de inserción a la docencia: Del eslabón perdido al puente para el desarrollo profesional docente. Documento elaborado para o Taller Internacional "Las políticas de inserción de los nuevos maestros en la profesión docente: La experiencia latinoamericana y el caso colombiano". Colombia, Bogotá, 2006. Disponível em: <http://www.ub.edu/obipd/docs/politicas de insercion a la docencia del eslabonperdido al puente para el desarrollo profesional docente garcia c m .pdf >. Acesso em: 27 jul. 2016.

TANCREDI, R. M. S. P. A aprendizagem da docência e profissionalização: elementos de uma reflexão. São Paulo: EdUfscar, 2009.

VAILLANT, D.; MARCELO, C. Ensinando a ensinar: as quatro etapas de uma aprendizagem. Curitiba: Ed. UTFPR, 2012.
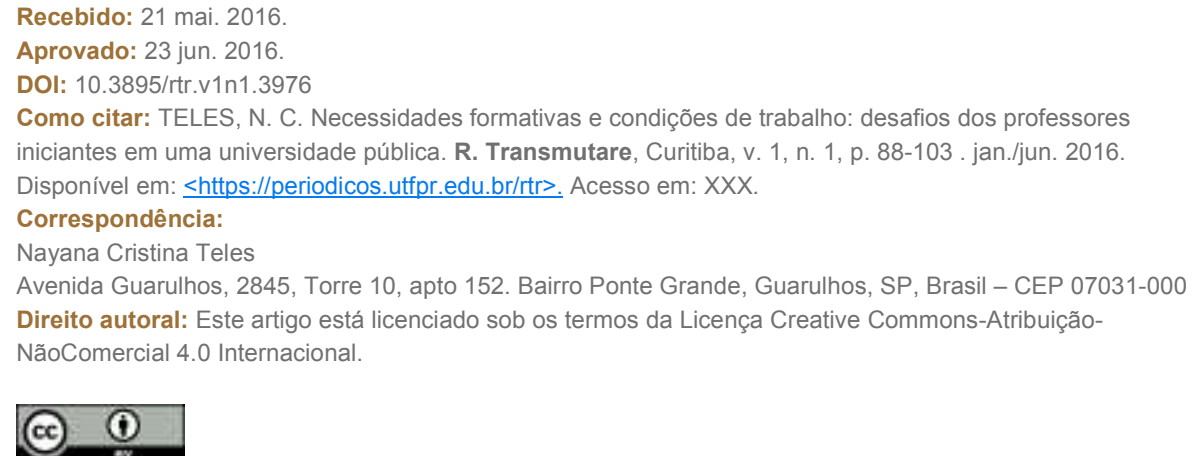